\title{
The last 11 years of Molteno implantation at the University of Cape Town. Refining our indications and surgical technique
}

\section{Abstract}

Aims To analyse outcomes, factors influencing surgical success, and surgical technique of Molteno implantation over the past 11 years in order to identify ways of improving long-term control.

Methods Retrospective interventional review of case records of all consecutive patients undergoing Molteno implantation at Groote Schuur Hospital between 1/1/1991 and 31/12/

Department of Surgery, Division of Ophthalmology, Faculty of Health Sciences, University of Cape Town and Groote Schuur Hospital, West Midlands, UK

\section{Correspondence:}

\section{Woodcock,}

Birmingham and

Midland Eye Centre, City Hospital, Dudley Road, Birmingham B18 7QH, UK Tel: + 447891655845 ; Fax: +441215076791. E-mail: malcolmwoodcock@ doctors.org.uk

Received: 15 December 2005

Accepted in revised form: 27 April 2006

Published online: 16 June 2006

Preliminary findings of this study were presented in part at the International

Glaucoma Congress, Cape Town, April 2005. The work has not been published elsewhere and the authors have no conflicts of interest 2002. Data were recorded on an MSAccess ${ }^{\mathrm{TM}}$ database and processed using Kaplan-Meier survival curves and life table analysis.

Results We analysed 162 consecutive singlephase Molteno tube implantation procedures on 157 eyes of 148 patients with mean followup of 2.9 years. Intraocular pressure (IOP) dropped from a mean of 43.3 at booking to 19.1 at final follow-up. Overall 'complete success' was achieved in $30 \%$ and 'partial success' in 16\%. A high preoperative IOP was a significant predictor of a high postoperative pressure. Pseudophakic patients had significantly better postoperative pressure control. Neovascular glaucoma was a risk factor for poor pressure control. Race, gender, previous surgery, uveitis, and trauma did not influence surgical outcome. Follow-up adjusted incidence of 2.4 cases of endophthalmitis per patient year was unexpectedly high. Tubes that migrated had been secured with absorbable sutures in 4/5 cases.

Conclusions In this study, high preoperative IOPs were probably a significant contributing factor to relatively poor postoperative pressure control. Addressing this issue may aid in improving outcomes in future surgery. The high postoperative pressure outcomes suggest that single plate Molteno implantation is not an ideal way of achieving low target pressure in third world glaucoma patients.

Eye (2008) 22, 18-25; doi:10.1038/sj.eye.6702473; published online 16 June 2006

Keywords: Molteno implants; intraocular pressure; glaucoma surgery; implant; device; seton

\section{Introduction}

Since Molteno implantation came into routine use in the 1980s patient selection, surgical technique and postoperative management have undergone steady evolution. In our population, glaucoma remains an important cause of blindness. Health economic factors as well as the rural location of large communities mean that for many of our patients consistent medical treatment is impossible and glaucoma surgery is the only feasible way of preventing blindness.

Our current practice is based largely on studies from our population in the early 1990s. ${ }^{1-4}$ Recently, excellent long-term results have been released from the more 'first-world', circumstances of Otago. ${ }^{5-8}$ As our surgical outcomes are less favourable, we aim to determine if our indications for surgery or technique should be modified further.

\section{Methods}

\section{Patients}

We report a retrospective interventional case series of 162 consecutive single-phase Molteno 
tube implantation procedures in 157 eyes of 148 patients over 11 years (1/1/1991-31/12/2001). Follow-up ranged between 6 months and 10 years (mean 2.9 years).

Patients underwent surgery for:

1. intractable glaucoma uncontrolled by medical treatment as well as trabeculectomy or,

2. as a primary procedure in those considered to have an unacceptably high risk of failure with trabeculectomy augmented with mitomycin C (MMC).

Of the 148 patients, six had bilateral Molteno implants, six had a second Molteno device implanted in the same eye, and one had three implant procedures in the same eye. The patient data recorded included sex, race, diagnosis, previous surgical procedures, treatment, visual acuity (VA), and intraocular pressure (IOP). Intraoperative data on the type of securing sutures, the use of vicryl tube ties, and antimetabolites were also recorded. Postoperative data included IOP at 6 months and annually thereafter, final VA and additional IOP lowering medical treatment needed.

\section{Surgical procedure}

Single plate implants were used in all cases. The plate was secured $10 \mathrm{~mm}$ posterior to the limbus in a subtenons pocket. If an encircling band was present the plate was secured to the band. It was sutured either with absorbable or nonabsorbable suture material as specified below. In most cases, the tube was ligated with a 6-0 vicryl suture. In selected cases, an additional prolene stent was included in the lumen of the tube in order to facilitate early pressure release. An upward facing bevel was cut, allowing for 2-3 mm extension into the eye and the tube was inserted via a $23 \mathrm{G}$ needle tract. In cases of anterior chamber insertion, a partial thickness scleral flap was used to cover the tube. In cases of pars plana insertion, the tube was inserted though an oblique $23 \mathrm{G}$ needle tract. The conjunctiva was closed and an injection of gentamicin and celestone was given subconjunctivally in the quadrant opposite to the Molteno implant.

\section{Criteria for success}

Complete success: IOP of $6-22 \mathrm{mmHg}$ with no treatment.

Partial success: IOP of $6-22 \mathrm{mmHg}$ with medical treatment.

Failure: IOP $<6 \mathrm{mmHg}$ or IOP $>22 \mathrm{mmHg}$.

\section{Statistical analysis}

Life tables and Kaplan-Meier survival curves were constructed. The survival of the various groups within the case series was compared using the log-rank test.
Crosstabulation $(2 \times 2)$ tables were also used with Pearson's $\chi^{2}$ test and Fisher's exact test to analyse the associations within the group.

\section{Results}

\section{Overall mean IOP}

IOP dropped from a mean of 43.3 at booking to 19.1 at final follow-up (see Figure 1).

\section{Success rate}

Overall 'complete success' was seen in 30\% and 'partial success' in an additional $16 \%$ of patients (Table 1). Failure was due to IOPs greater than 22 in $43 \%$ of the overall group and hypotony in 11\%. The Mixed Race group (116) were the largest racial group in the series followed by Black (25), then White (17), and finally Indian (3). The male to female ratio was $1.1: 1$ (74:67). Race and gender had no statistically significant effects on the outcome of tube implantation.

\section{Type of glaucoma}

A reduction in IOP was seen in all types of glaucoma, although the success rates did vary between diagnostic groups (Table 1). Patients with neovascular glaucoma (NVG) did significantly worse than those with primary open-angle glaucoma $(P=0.0321)$, secondary open-angle glaucoma $(P=0.0321)$, and secondary angle closure glaucoma $(P=0.0042)$. There were no significant differences in outcome between NVG and the other groups or between the other diagnostic groups themselves (Table 2). Figure 2 shows the Kaplan-Meier survival curves for each type of glaucoma. NVG could be

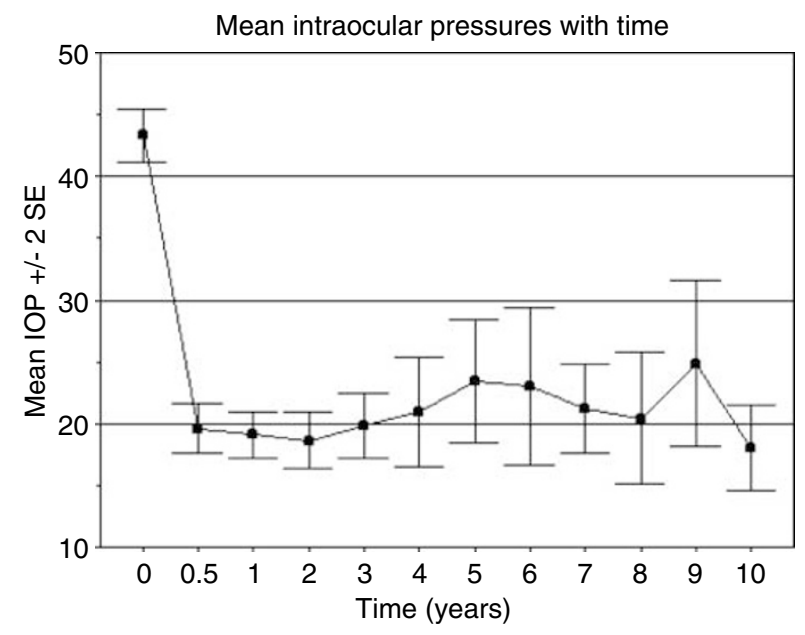

Figure 1 Mean IOP with time. 
broken down into two main groups dependent on the aetiology of the neovascularisation in 75 of the 84 cases. In the nine cases, the aetiology was either unclear or there was insufficient information in the notes to be sure of the cause. Proliferative diabetic retinopathy (PDR) caused the glaucoma in 44 patients and vein occlusion was the cause in 31 of the patients. There was no statistical difference in the IOP profiles between these two groups. This group also did badly in terms of VA with $43 \%$ ending up with no perception of light (NPL). There was no statistical difference in the percentages of PDR diabetics with NVG becoming NPL (39\%) and patients with vein occlusions becoming NPL (48\%).

\section{Preoperative IOP}

Overall, patients with an IOP of $>35 \mathrm{mmHg}$ preoperatively had poorer ultimate IOP control than those who had preoperative IOPs of $\leqslant 35 \mathrm{mmHg}$ $(P=0.008)$. This difference remained when the NVG group were looked at alone $(P=0.05)$ but was not significant in the other types of glaucoma once NVG had been excluded $(P=0.27)$. NVG patients tended to have higher presenting IOPs than the other groups. For preoperative IOPs of greater than $30 \mathrm{mmHg}$ compared to IOPs of $30 \mathrm{mmHg}$ or less, when the NVG patients were excluded, the significance jumped markedly to $P=0.08$,

Table 1 Overall success rate at final follow-up

\begin{tabular}{lccc}
\hline Type of glaucoma $(\mathrm{n})$ & $\begin{array}{c}6 \leqslant I O P \leqslant 22 \\
\text { no } R x(\%)\end{array}$ & $\begin{array}{c}6 \leqslant I O P \leqslant 22 \\
\text { on } R x(\%)\end{array}$ & $\begin{array}{c}\text { Failure } \\
(\%)\end{array}$ \\
\hline All patients (162) & 30 & 16 & 54 \\
Neovascular (84) & 25 & 10 & 65 \\
Primary open angle (8) & 44 & 28 & 28 \\
Primary chronic angle & & 100 & \\
closure (2) & 33 & 19 & 48 \\
Secondary open angle (48) & 43 & 25 & 31 \\
Secondary angle closure (17) & & 34 & 66 \\
Developmental (3) & {$[33]^{\mathrm{a}}$} & {$[17]^{\mathrm{a}}$} & {$[50]^{\mathrm{a}}$} \\
\hline Trauma (24)] & & & \\
\hline
\end{tabular}

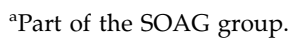

although still fell outside our benchmark level of $P=0.05$.

\section{Modulation and medication}

Antimetabolites were used in 19 cases (MMC 17, 5-flurouracil 2) and a postoperative antifibrosis regimen (prednisolone, diclofenac, and colchicine systemically) was used in three patients. These modulations made no statistically significant difference to the long-term IOP profiles of these patients when compared to those that were treated with a standard regimen of topical steroids and atropine postoperatively. Furthermore, there was no increased incidence of postoperative hypotony in the groups treated with antimetabolites.

In total, $119(73 \%)$ of the patients were using medical IOP lowering agents preoperatively (13 on one treatment, 76 on two and 30 on three) with an average number of 1.57 agents overall. Postoperatively, 47 (29\%) patients were on IOP lowering treatments (28 on one treatment, 11 on two and eight on three) with an average number of 0.46 agents overall. This postoperative reduction in the number of patients using medications and the numbers of medications used was statistically significant $(P<0.001)$.

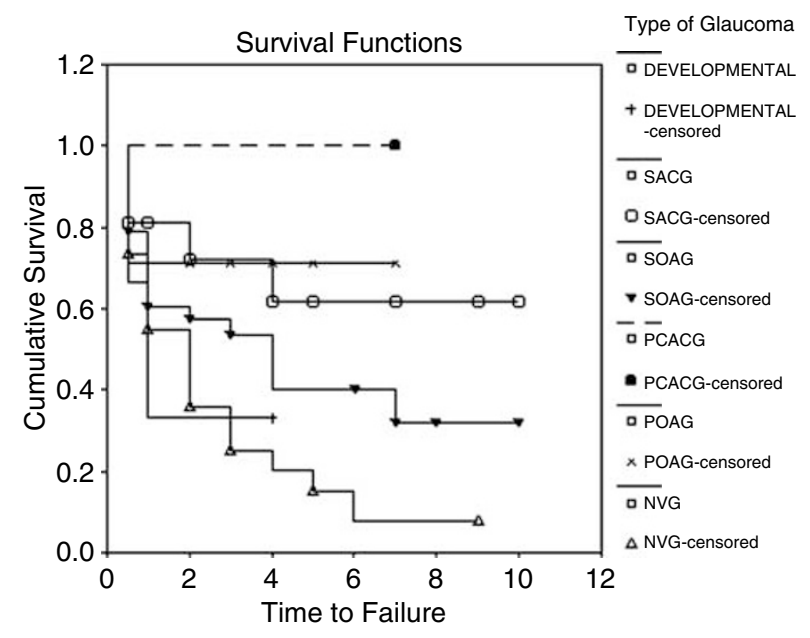

Figure 2 Survival functions.

Table 2 Individual types of glaucoma compared to each other with log-rank statistic and (significance)

\begin{tabular}{llcccr}
\hline & \multicolumn{1}{c}{ NVG } & POAG & PCACG & SOAG & SAGG \\
\hline POAG & $4.59(0.0321)^{\mathrm{a}}$ & & & & \\
PCACG & $2.49(0.1143)$ & $0.33(0.5637)$ & & & \\
SOAG & $4.59(0.0321)^{\mathrm{a}}$ & $1.09(0.2961)$ & $1.15(0.2827)$ & & \\
SACG & $8.18(0.0042)^{\mathrm{a}}$ & $0.02(0.8756)$ & $0.47(0.4941)$ & $1.94(0.1638)$ & $1.31(0.2526)$ \\
Developmental & $0.01(0.9329)$ & $0.96(0.3284)$ & $0.83(0.3621)$ & $0.23(0.6326)$ & \\
\hline
\end{tabular}

aStatistically significant. 


\section{Pseudophakia}

The patients who had undergone previous cataract surgery (35) had significantly better postoperative IOP profiles than the phakic (127) patients $(P=0.03$, see Figure 3). This was despite the fact that the pseudophakic group included more patients with NVG than the phakic group (56 vs 50\%). There were eight aphakic patients among 35 in the cataract surgery group. When these were separated out, the significance of the difference between pseudophakic (27) and phakic patients fell to $P=0.058$. The small proportion of aphakic patients precluded statistical analysis of their IOP profiles in comparison with the other groups.

\section{Previous glaucoma surgery, trauma, and uveitis}

There was no significant difference in the outcome of surgery in patients with a history of previous glaucoma surgery (37), trauma (24), or uveitis (six).(See Table 3 for a summary of variables influencing outcome.)

\section{Surgery: technique and complications}

Seventy-one of the Molteno implants were secured with absorbable sutures and 59 with nonabsorbable sutures. Of the five tubes that migrated from their intended position, four had been secured with absorbable sutures. This difference was not statistically significant (Fisher's exact test $P=0.492$ ). A vicryl tie was used to occlude the tube in 146 cases (90\%). The incidence of hypotony was $17 \%$ in the group where a tie was used compared to $31 \%$ in the 16 in which no tie was used. This difference was not statistically significant (Fisher's exact test $P=0.180$ ).

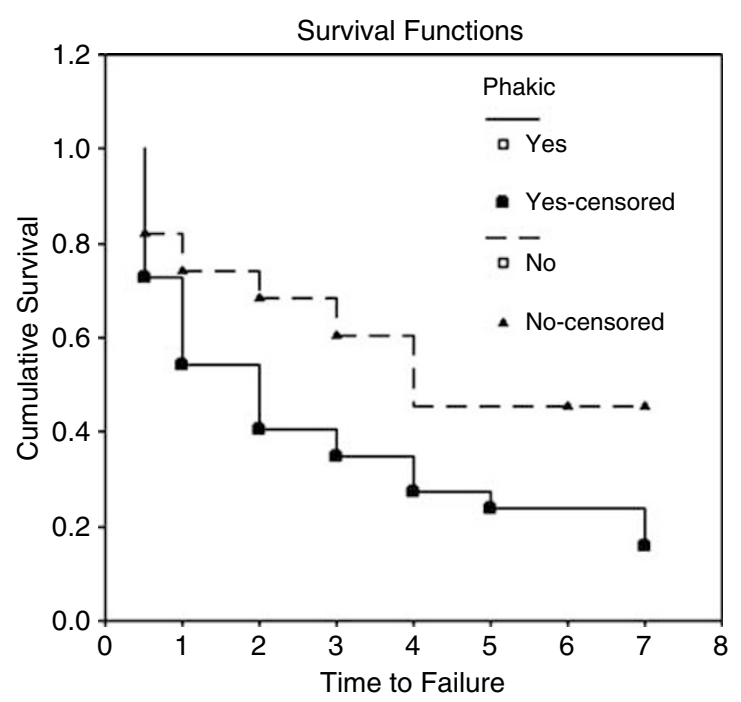

Figure 3 Survival functions.
Exposure of the Molteno tube through the conjunctiva occurred in seven patients and was not associated with the use of antimetabolites or any other variable examined. (See Table 4 for a summary of other complications.)

Endophthalmitis occurred in a total of seven eyes, a follow-up adjusted incidence of 2.4 cases of endophthalmitis per patient year. Three patients had exposed tubes, of whom only one had received intraoperative MMC. There were no other identifiable risk factors. Five patients ultimately had the eye removed (three NVG, one SOAG, one developmental), three as a result of endophthalmitis and two because of continuing discomfort.

The majority of the drainage tubes were placed in the anterior chamber (152) with only nine being placed directly through the pars plana. There was no difference in the IOP profiles of these two groups.

\section{Discussion}

\section{Outcomes}

Based on current evidence, it is desirable to maintain IOPs in the low teens in order to minimise progression of optic nerve damage. ${ }^{18}$ In our series, mean IOP dropped from $43.3 \mathrm{mmHg}$ to 19.1 at final follow-up. This is considerably higher than the IOP in the mid teens, $, 10,19$ reported in several other series including one with similar starting IOP to ours of 42.4 dropping to $16.8 .^{11}$ The mean final postoperative IOP of the POAG group was $19.2 \mathrm{mmHg}$. Unfortunately, this finding suggests that single plate Molteno implantation is not appropriate for managing the majority of our primary open-angle glaucoma cases where IOP in the low teens is required.

In comparison with the Otago experience, ${ }^{5-8}$ our overall success rate of $46 \%$ appears dismal. Our results do, however, appear to be similar to comparable series

Table 3 Overall summary of variables influencing outcome

\begin{tabular}{ll}
\hline Significant variables & Nonsignificant variables \\
\hline NVG do worse than POAG & Race \\
NVG do worse than SOAG & Gender \\
NVG do worse than SACG & Previous glaucoma surgery \\
Preop IOPs $>35$ do worse & Antimetabolites \\
than preop IOPs $\leqslant 35$ & (IOP, endophthalmitis, \\
Phakic patients do worse & tube exposure) \\
than those that have had & Trauma \\
cataract surgery & Uveitis \\
Patients on fewer IOP & Tube position \\
medications postoperatively & Aetiology of NVG \\
than preoperatively & \\
\hline
\end{tabular}


Table 4 Complications summary

\begin{tabular}{|c|c|c|c|c|c|c|c|c|c|c|c|c|c|}
\hline Reference no. & & 2,3 & 6 & 9 & 10 & 11 & 12 & 13 & 14 & 15 & 16 & 17 & 17 \\
\hline Author & $\begin{array}{c}\text { Woodcock } \\
2006\end{array}$ & $\begin{array}{c}\text { Mermoud } \\
1992\end{array}$ & $\begin{array}{c}\text { Molteno } \\
2001\end{array}$ & $\begin{array}{c}\text { Neelkantan } \\
1994\end{array}$ & $\begin{array}{l}\text { Price } \\
1995\end{array}$ & $\begin{array}{c}\text { Valimaki } \\
1998\end{array}$ & $\begin{array}{l}\text { Mills } \\
1996\end{array}$ & $\begin{array}{c}\text { Minckler } \\
1988\end{array}$ & $\begin{array}{c}\text { Broadway } \\
2000\end{array}$ & $\begin{array}{l}\text { Lloyd } \\
1992\end{array}$ & $\begin{array}{c}\text { Freedman } \\
1991\end{array}$ & $\begin{array}{c}\text { Heuer } \\
1992\end{array}$ & $\begin{array}{c}\text { Heuer } \\
1992\end{array}$ \\
\hline Single or double plate & Single & Single & Mix & Single & 85\% Double & $92 \%$ Single & Mix & Single & Mix & Single & Single & Double & Single \\
\hline Total number & $162(\%)$ & $120(\%)$ & $130(\%)$ & $62(\%)$ & $76(\%)$ & $87(\%)$ & $77(\%)$ & $90(\%)$ & $119(\%)$ & $96(\%)$ & $83(\%)$ & $50(\%)$ & $49(\%)$ \\
\hline Follow-up years (range) & $3(0.5-12)$ & $1.9(0.25-5)$ & $4.4(1-12)$ & $0.4(0.1-1.4)$ & $2.75(1.5-5.3)$ & 2 & $3.6(0.5-9)$ & $1.3(0.5-2.5)^{\mathrm{a}}$ & 3.6 & $4(0.5-6.5)$ & 2.5 & $1.4^{\mathrm{a}}$ & $1.2^{\mathrm{a}}$ \\
\hline Hypotony & $30(18)$ & & & & $4(5.2)$ & & $3(4)$ & $2(2.2)$ & $5(4.2)$ & & & & \\
\hline Flat a/c & $24(14)$ & $13(11)$ & $4(3)$ & & & $9(13)$ & $3(4)$ & $2(2.2)$ & $9(7.6)$ & $3(3)$ & $10(12)$ & $5(10)$ & $2(4)$ \\
\hline Hyphema & $12(7.4)^{\mathrm{b}}$ & $18(15)$ & $8(6)$ & $2(3)$ & $7(9.2)$ & $10(14)$ & $9(12)$ & $1(1.1)$ & $1(0.8)$ & $2(2)$ & $15(18)$ & $2(4)$ & $1(2)$ \\
\hline Vitreous haemorrhage & $1(0.5)$ & & & $1(1.6)$ & & $1(1)$ & $5(7)$ & $1(1.1)$ & & $2(2)$ & & $2(4)$ & \\
\hline Choroidal effusion & $12(7.4)$ & $4(3.3)$ & $20(15)$ & $14(23)$ & $9(12)$ & $11(15)$ & $4(5)$ & $2(2.2)$ & $18(15.1)$ & $3(3)$ & $5(6)$ & $2(4)$ & \\
\hline Choroidal haemorrhage & & & & & & $2(3)$ & & $7(7.7)$ & $1(0.8)$ & $5(5)$ & & $6(12)$ & \\
\hline Corneal oedema & & $12(10)$ & & & & $2(3)$ & & $1(1.1)$ & & $18(19)$ & & & $1(2)$ \\
\hline Corneal decompensation & $5(3)$ & $4(3.3)$ & $2(1.5)$ & & & & $8(10)$ & & $9(7.6)$ & & & $5(10)$ & $3(6)$ \\
\hline Corneal graft failure & & & & & & & $6(8)$ & $4(4.4)$ & $3(2.5)$ & $12(12)$ & & & \\
\hline Tube cornea touch & $6(3.6)$ & $8(6.6)$ & & $5(8)$ & & $6(8)$ & $2(3)$ & $3(3.3)$ & & $8(8)$ & & & $1(2)$ \\
\hline Corneal ulcer & $1(0.5)$ & $1(0.8)$ & & & & $3(4)$ & & & & $2(2)$ & & & \\
\hline Corneal melt & & & & & & & & & & $1(1)$ & & & \\
\hline Tube erosion/exposure & $12(7.4)$ & $3(2.5)$ & & $1(1.6)$ & $3(4)$ & $4(6)$ & $4(5)$ & $3(3.3)$ & $9(7.6)$ & $3(3)$ & $1(1.2)$ & $2(4)$ & $1(2)$ \\
\hline Tube obstruction & $5(3)$ & $7(6)$ & & $3(5)$ & $12(16)$ & $11(15)$ & $13(17)$ & $5(5.5)$ & $10(8.4)$ & $4(4)$ & $5(6)$ & $1(2)$ & $1(2)$ \\
\hline Tube retraction & $3(2)$ & $3(2.5)$ & & $1(1.6)$ & & & & $1(1.1)$ & & $2(2)$ & & & \\
\hline Persistent uveitis & & & & $9(14.5)$ & & $2(3)$ & & & $9(7.6)$ & $1(1)$ & & $1(2)$ & \\
\hline Retinal detachment & $5(3)$ & & & $4(6.4)$ & $3(4)$ & & $1(1)$ & $3(3.3)$ & $6(5.6)$ & $8(8)$ & & $1(2)$ & $1(2)$ \\
\hline Endophthalmitis & $7(4.3)$ & & & & $1(1.3)$ & & & & & & & $1(2)$ & \\
\hline Cataract & & & $22(17)$ & & & $8(11)$ & $3(4)$ & $6(6.6)$ & $3(2.5)$ & $8(8)$ & $4(4.8)$ & & \\
\hline Strabismus & & & & & $2(2.6)$ & & & & $3(2.5)$ & $1(1)$ & & & \\
\hline Phthisis bulbi & & $11(9)$ & & $2(3)$ & $6(8)$ & & $6(8)$ & $1(1.1)$ & & $6(6)$ & $4(4.8)$ & $2(4)$ & \\
\hline Encapsulated bleb & $5(3)$ & $11(9)$ & & & & & & & & & $14(17)$ & & \\
\hline Epiretinal membrane & & & & & & & $9(12)$ & & & $2(2)$ & & & \\
\hline Malignant glaucoma & & & & & & & $1(1)$ & & & $1(1)$ & & & \\
\hline BRVO & & & & & & & & & & $2(2)$ & & & \\
\hline Late ocular pain & & $4(3.3)$ & & & & & & & & & & & \\
\hline
\end{tabular}

a Follow up for successes only.

${ }^{\mathrm{b}}$ All but one in neovascular glaucoma group. 
from the 1990s. In these groups, success rates varied from $100 \%$ with IOP 20 or less for single plate two-stage implantation in Molteno's hands (using Molteno's antifibrosis regime) to $47 \%$ for single plate one-stage implantation. ${ }^{10,12,20}$

\section{Factors influencing outcome}

Patient groups

There was no statistically significant association between race and the success of the surgery in our series. This is in keeping with the findings of other studies, ${ }^{21,22}$ and in contrast with findings for trabeculectomy. ${ }^{23,24}$ Stewart et $a l^{21}$ in a consecutive series of 38 patients treated with single plate Molteno implants with prolene stents pulled at 3 weeks found that age, race, sex, glaucoma type, phakic status, bleb elevation, medical history, previous surgery, or number of glaucoma medications had no influence on success at 6 months postop (defined as IOP of 18 or less). Patients with early postoperative pressure elevation (usually occurring around the third week) were less likely to have long-term IOP control.

Similarly, our overall differences in success rate between the types of glaucoma, excluding neovascular glaucoma, were not statistically significant. Of note, however, were our poor results with NVG when analysed individually against select glaucoma groups (see Table 3). Previous publications suggest that NVG, particularly that resulting from vascular occlusion, has a poor prognosis and glaucoma surgical success rate. ${ }^{1,12,14,15}$ A particularly important and interesting finding in our study was that preoperative IOP $>35 \mathrm{mmHg}$ was significantly predictive of poor success in attaining long-term IOP control in patients with NVG. Our success rate of $35 \%$ in this group was in keeping with findings from other studies in which both single and double plate implants were used..$^{12,14,15}$ In a series of 119 eyes treated with double or single plate implants, IOP reduction following surgery was lowest for NVG. ${ }^{14}$ In a previous series of 60 eyes with NVG in our community, the success rate was $62.1 \%$ at 1 year falling to $10.3 \%$ at 5 years (with $48 \%$ losing light perception and $18 \%$ progressing to phthisis bulbi), although $94 \%$ remained quiet and comfortable. ${ }^{1}$ In this study, eyes with diabetic retinopathy had a better prognosis than those with vein occlusion. No comparison was reported between diabetics and vein occlusions on grounds of IOP alone. In contrast, our study found that diabetics with NVG fared no better in terms of IOP or vision than those with vein occlusions. Patients with NVG fared no worse than other groups in terms of enucleation or long-term pain. No randomised studies have been conducted comparing visual and IOP success in NVG patients receiving double with those receiving single plate implants. The evidence available suggests the continued use of less expensive single plate implants in this group of patients is justified, particularly in those for whom the goal is pain prevention. In future, Molteno implant studies NVG patients should be analysed separately from other groups.

The nonstatistically significant trend towards higher preop IOP predicting higher postop IOP may account for some of the difference in success rate between our series and the Otago results for primary glaucoma. ${ }^{6}$ In that group mean preoperative IOP was only $23.66 \mathrm{mmHg}$ compared with $43.3 \mathrm{mmHg}$ in our series. Anecdotally, it has been speculated that 'high pressure' aqueous is more fibrogenic than 'low pressure' aqueous. It is postulated that preventing IOP elevation postoperatively leads to better functioning blebs with lower IOP in the long term. ${ }^{25}$ This is one of the reasons given for the desirability of a vicryl ligature to prevent 'high pressure' aqueous from entering the bleb in preference to early release of a prolene stent. Unfortunately, no biochemical explanation is yet available for the 'high pressure aqueous' theory and these observations may just be related to the degree of outflow obstruction at the drainage angle, which in most cases will not be altered by the surgery. Of note, no significant difference in success rate has been found between partial and total tube ligation. ${ }^{11}$ Results in the series where the tube was opened at 7-10 days were, if anything better than ours in which the majority of implant tubes were ligated with vicryl and allowed to open after approximately 6 weeks. In that series of 62 single plate Molteno implantations, the mean postoperative IOP was 16.97 and $74.19 \%$ of patients had IOP of 21 or less at 72 weeks.9

In contrast with trabeculectomy, local chemical modulation had no effect on long-term success (or complications) of Molteno implantation in this series. ${ }^{9}$ This concurs with the report of Lee $e t a l^{22}$ which showed MMC had no effect on survival, IOP,or number of medications. We did not look at the early hypertensive phase in which it appears that MMC might have an attenuating effect. ${ }^{26-28}$

Our drop in average number of 1.57 medications preop to 0.46 medications postop is comparable to that in the Otago series where patients were using a mean of 1.96 preop and 0.63 postop. ${ }^{6}$ During the study,patients in our community had ready access to beta-blockers, oral carbonic anhydrase inhibitors, and pilocarpine. Only the more motivated or better off patients could obtain alpha-2-agonists regularly. Prostanoids and topical carbonic anhydrase inhibitors were not available. This situation remains unchanged and may partially account for our high pre-and postoperative IOP in our patients. Their socioeconomic disadvantage and poor access to regular follow-up and medication are also likely to play a role in our IOP figures. 
Interestingly, the patients who had undergone previous cataract surgery in our series had significantly better postoperative IOP profiles than phakic patients $(P=0.03$, see Figure 2$)$. This was despite the fact that pseudophakic group included more patients with NVG than the phakic group (56 vs 50\%). Our findings were in contrast with those from a retrospective 10-year consecutive case series of 119 eyes treated with double or single plate implants using the vicryl tie technique. ${ }^{14}$ In that series, pseudophakia was the only identifiable risk factor for failure. Previous ocular surgery, age, sex, and race had no significant effect on outcome. ${ }^{14}$ The Otago group reported that 10 years after surgery, Molteno implantation resulted in $100 \%$ success and statistically significantly better IOP control than trabeculectomy when combined with cataract extraction. ${ }^{5}$

There was no significant difference in the outcome of surgery in patients who had a history of previous glaucoma surgery (37) or developed glaucoma as a result of trauma (24) or uveitis (6). Our series did not contain many uveitis patients, which may account for the fact that we did not see better results in this group. Other studies suggest that the uveitis group may have particularly favourable results following Molteno implantation. ${ }^{7,14}$

\section{Surgery and complications}

An important clinically significant (although not statistically significant) finding in our series was that $4 / 5$ tubes that migrated had been secured with absorbable suture material. As no complications occurred with nonabsorbable suture material, there is no justification in using absorbable material and we have ceased this practice.

Tube exposure occurred in seven of our patients, three of whom developed endophthalmitis. It is often prevented in other series by use of a donor scleral patch. In our population, there is heightened concern about disease transmission through the use of biological products. There are also the cost implications of using donor sclera that cannot be ignored in state or charitable hospitals operating in the developing world. As a result up until now, we have only been using scleral patches if tube exposure occurs.

The follow-up adjusted incidence of endophthalmitis of 2.4 cases per patient year was disappointing, although notably no cases occurred in patients with primary glaucoma. Our patients' poor socioeconomic circumstances, and the health problems associated with such conditions, are likely to put them at greater risk of infection. These findings support the case for using donor sclera in Molteno implantation in our population.

\section{Choice of implant}

Despite evidence for lower IOP after double plate implantation, our department has been using single plate implants, mainly because of financial limitations. In 1981, Molteno published a small series of 20 eyes in which single, double and four plate implants were compared. Follow-up times were not specified. In that study of moderate risk patients it was found that the risk of early postoperative hypotony following single-stage implantation was similar in single and double plate devices. The 'long-term' IOP was much higher in single plate $(25 \mathrm{mmHg})$ than double $(12.75 \mathrm{mmHg})$ or four plate $(10.6 \mathrm{mmHg})$ devices. ${ }^{29}$ In a subsequent publication concerning patients with primary glaucoma from the same population, it was found that IOP after double or single plate implantation differed by only $0.73 \mathrm{mmHg}$. Mean IOP after 2-8 years follow-up remained between 13.9 and $14.8 \mathrm{mmHg}$ from a mean preoperative IOP of $23.66 \mathrm{mmHg}$. The authors attributed the lack of difference in IOP between one or two plates to appropriate selection of either type of implant. ${ }^{6}$ In a prospective randomised trial of single $v$ s double plate implants success rates of $6-20 \mathrm{mmHg}$ at 1 and 2 years for single implants were 55 and $46 \%$ and for double plate implants were 86 and $71 \%$. Mean IOP was not reported. ${ }^{17}$ The disappointingly high IOP outcomes in our series suggest that double plate implants should be used in patients where lower target IOP is vital.

The patients treated with Molteno implants in our study group were those with the poorest prognosis and our failure rate and the number of complications encountered reflects this. In addition, many of our patients live in difficult socioeconomic circumstances in areas with poor sanitation. Timely access to eye care and medication is often difficult and expensive. The high postoperative pressure outcomes suggest that single plate Molteno implantation is not an ideal way of achieving low-target pressure in third-world glaucoma patients. Reducing the risk of tube exposure and subsequent endophthalmitis by using scleral patch grafts would be of benefit but must be weighed up against the financial cost involved as well as the potential for disease transmission. We advise that Molteno drainage devices should be secured with nonabsorbable suture material to reduce the risk of subsequent implant migration.

\section{References}

1 Mermoud A, Salmon JF, Alexander P, Straker C, Murray ADN. Molteno tube implantation for neovascular glaucoma. Ophthalmology 1993; 100: 897-902.

2 Mermoud A, Salmon JF, Barron A, Straker C, Murray ADN. Surgical management of post-traumatic angle recession glaucoma. Ophthalmology 1993; 100: 634-642. 
3 Mermoud A, Salmon JF, Straker C, Murray A. Use of the single-plate Molteno implant in refractory glaucoma. Ophthalmologica 1992; 205: 113-120.

4 Salmon JF, Sebastiani A. The use of the Molteno long-tube implant in the management of neovascular glaucoma. Clin Ocul 1990; (3): 169-173.

5 Molteno A, Whittaker K, Bevin T, Herbison P. Otago glaucoma surgery outcome study: long term results of cataract extraction combined with Molteno implant insertion or trabeculectomy in primary glaucoma. $\mathrm{Br} \mathrm{J}$ Ophthalmol 2004; 88: 32-35.

6 Molteno ACB, Bevin TH, Herbison R, Houliston M-J. Otago glaucoma surgery outcome study long-term follow-up of cases of primary glaucoma with additional risk factors drained by Molteno implants. Ophthalmology 2001; 108: 2193-2200.

7 Molteno ACB, Sayawat N, Herbison P, Otago Glaucoma Survey Outcome Study. Long-term results of uveitis with secondary glaucoma drained by Molteno implants. Indian J Ophthalmol 2001; 108: 605-613.

8 Fuller JR, Bevin TH, Molteno ACB. Long-term follow-up of traumatic glaucoma treated with Molteno implants. Ophthalmology 2001; 108: 1796-1800.

9 Neelkantan A, Rao S, Vijaya L, Krishnan N, Priya VS. Single-plate Molteno implants in complicated glaucomas: results, survival rates, and complications. Indian J Ophthalmol 1994; 42(2): 193-197.

10 Price FW, Wellemeyer M. Long-term Results of Molteno implants. Ophthalmic Surg 1995; 26(2): 130-135.

11 Valimaki J, Tuulonen A, Airaksinen PJ. Outcome of Molteno implantation surgery in refractory glaucoma and the effect of total and partial tube ligation on the success rate. Acta Ophthalmol Scand 1998; 76: 213-219.

12 Mills RP, Reynolds A, Emond MJ, Barlow WE, Leen MM. Long-term survival of Molteno glaucoma drainage devices. Ophthalmology 1996; 103: 299-305.

13 Minckler DS, Heuer DK, Hasty B, Baerveldt G, Cutting RC, Barlow WE. Clinical experience with the single-plate Molteno implant in complicated glaucomas. Ophthalmology 1988; 95: 1181-1188.

14 Broadway DC, Lester M, Schulzer M, Douglas GR. Survival analysis for success of Molteno tube implants. $\mathrm{Br} J$ Ophthalmol 2001; 85: 689-695.

15 Lloyd MA, Sedlak T, Heuer DK, Minckler DS, Bacrveldt G, Lee $\mathrm{MB}$ et al. Clinical experience with single-plate Molteno implant in complicated glaucomas. Ophthalmology 1992; 99: 679-687.

16 Freedman J, Rubin B. Molteno implants as a treatment for refractory glaucoma in Black patients. Ophthalmology 1991 109: 1417-1420.

17 Heuer HK, Lloyd MA, Abrams DA et al. Which is better? one or two? A randomised clinical trial of single plate versus double-plate Molteno implantation of glaucomas in aphakia and pseudophakia. Ophthalmology 1992; 99: 1512-1519.

18 Palmberg P. How clinical trial results are changing our thinking about target pressures. Curr Opin Ophthalmol 2002; 13: $85-88$.

19 Freedman J. The use of the single stage Molteno long tube seton in treating resistant cases of glaucoma. Ophthalmic Surg 1985; 16(8): 480-483.

20 Melamed S, Fiore PM. Molteno implant surgery in refractory glaucoma. Surv Ophthalmol 1990; 34: 441-448.

21 Stewart WC, Connor AB, Pitts RA. Prognostic factors and post-operative course following single-plate Molteno implantation. Doc Ophthalmol 1994; 86: 409-417.

22 Lee D, Shin DH, Birt CM, Kim C, Kupin TH, Olivier MMG et al. The effect of mitomycin C in Molteno implant surgery. Ophthalmology 1997; 104: 2126-2135.

23 Mwanza J, Kabasele P. Trabeculectomy with and without mitomycin-C in a black African population. Eur J Ophthalmol 2001; 11(3): 261-263.

24 Broadway D, Grierson I, Hitchings R. Racial differences in the results of glaucoma filtration surgery: are racial differences in the conjunctival cell profile important? $\mathrm{Br} J$ Ophthalmol 1994; 78(6): 466-775.

25 Molteno A, Dempster A, Carne A. Molteno implants: the principles of bleb management. Aust NZ J Ophthalmol 1999; 27: 350-353.

26 Ellingham RB, Morgan WH, Westlake W, House PH. Mitomycin $\mathrm{C}$ eliminates the short-term intraocular pressure rise found following Molteno tube implantation. Clin Exp Ophthalmol 2003; 31: 191-198.

27 Oguz H. Mitomycin C and Molteno tube implantation. Clin Exp Ophthalmol 2003; 31: 458.

28 Ellingham RB, Morgan WH, Westlake W, House PH. Mitomycin $\mathrm{C}$ and Molteno tube implantation: reply. Clin Exp Ophthalmol 2003; 31: 458-459.

29 Molteno A. The optimal design of drainage implants for glaucoma. Trans Ophthal Soc NZ 1981; 33: 39-42. 